\title{
OPTIMIZATION ANALYSIS OF CONSTRUCTION SCHEME FOR LARGE-SPAN HIGHWAY TUNNEL UNDER COMPLEX CONDITIONS
}

\begin{abstract}
Jiao Pengfei ${ }^{1}$, Xiao Zhang ${ }^{1}$, Xinzhi Li ${ }^{1}$, Bei Jiang ${ }^{1,3}$, Bohong Liu ${ }^{1}$, Haojie Zhang ${ }^{1}$
Abstract: The construction process of the tunnel ground deformation regularity of surrounding rock, stability, deformation control of tunnel surface based on the requirements, combined with the characteristics of shallow tunnel with large-span. Used three-dimensional numerical simulation software, established a dynamic tunnel analysis program to simulate the construction process of center cross-diagram method and double sidewall drift method. Based on the stratum deformation, supporting force and analysis of plastic zone distribution, comparative analysis of engineering adaptability of different construction methods from the construction process and construction mechanics, get optimization tunnel construction scheme.
\end{abstract}

Keywords: similar materials, large-span, center cross-diagram method, double sidewall drift method

\footnotetext{
${ }^{1} \mathrm{PhD}$ student, Shandong University, Research Center of Geotechnical and Structural Engineering, 250061, China, e-mail:jiaopengfei1202@163.com

${ }^{2} \mathrm{PhD}$ student, Shandong University, Research Center of Geotechnical and Structural Engineering, 250061, China, e-mail:zhangxiaosdu@126.com

${ }^{3} \mathrm{PhD}$ student, Shandong University, Research Center of Geotechnical and Structural Engineering, 250061, China, e-mail:lixinzhisdu@126.com

${ }^{4} \mathrm{PhD}$, University of Jinan, School of Civil Engineering and Architecture, 250022, China, e-mail:jiangbeisdu@126.com

5 M.S, Shandong University, Research Center of Geotechnical and Structural Engineering, 250061, China, e-mail:lbhsteve@126.com

6 M.S, Shandong University, Research Center of Geotechnical and Structural Engineering, 250061, China, e-mail:zhanghaojie0911@163.com
} 


\section{INTRODUCTION}

In recent years, with the rapid development of domestic economy, higher requirements for traffic construction have been put forward. The number of Expressway lanes is increasing. The large-span tunnel with three lanes has become a common form of tunnel structure in recent years. The large-span shallow tunnel excavation impact on the surface environment is obvious, because of the depth of rock affected by tectonic movement surface rock weathering serious, high strength, bad rock, usually below grade V surrounding rock, and the construction of serious disturbance to the surrounding rock, the surface generated by the ground loss and deformation of surface environment. The more obvious, especially for the three lane tunnel, the buried depth, span, control put forward higher requirements on the surface deformation of tunnel construction.

Y.Q. Liu used china's first ultra small spacing tunnel Zhaobaoshan tunnel as a practical engineering calculation, finite element numerical simulation of tunnel construction condition of the construction of the ground subsidence, vault settlement and convergence, surrounding rock displacement, surrounding rock pressure and supporting structure of surrounding rock strain, relaxation range and depth of blasting damage to test the system, accurately grasp the mechanical state of tunnel in different construction process, to ensure the smooth construction of tunnel[1] .

T.L. Cui Taking forest and Village section excavation project in Guangzhou Metro as an example, the radial pressure and internal force distribution law of surrounding rock of super shallow buried tunnel were obtained by means of structural internal force monitoring, and the stability analysis of surrounding rock pressure and structural internal force was carried out [2].

A.Q. Wu Taking the Underground Powerhouse Rock Mechanics Test and stress test results for the basic data, using the finite element numerical calculation, rock mass classification, rock block analysis, the stability of surrounding rock of underground powerhouse problems were studied, and the stability of the surrounding rock and the necessary supporting measures are discussed [3].

Y.Z. $\mathrm{Lu}$ introduced an example of construction scheme of a $23.4 \mathrm{~m}$ span multi arch tunnel excavation, wall construction method and UDEC type switch in the excavation are discussed in detail [4].

M.J. WU used highway tunnel structure and rock experiment system (CTSSSRH) and the finite 
element analysis program, the dynamic construction process of four lane highway tunnel in different construction methods of physical model test and Numerical Simulation Research on four lane highway tunnel surrounding rock and structure displacement, distribution and development rules of stress and strain and damage zones the dynamic construction mechanical characteristics of four lane highway tunnel in different construction methods, and puts forward the reasonable construction method [5] .

W.Q. Ding in Longshan tunnel arch has the characteristics of shallow large span arch tunnel construction, established the dynamic finite element analysis program, simulation three pilot drift method and step excavation method of double arch tunnel construction process, and through the arch settlement, surface subsidence, wall should be in force, stability analysis of the surrounding rock that makes the actual tunnel construction scheme optimization [6].

Y.X. Zhang selected the Beijing Chengde Expressway Hejiagou tunnel as the research object, the tunnel is on the downstream separation type double hole one-way tunnel excavation section for straight wall arch. Using three-dimensional fast Lagrange method, study the mechanical behavior of highway tunnel excavation and support in the process of distribution in dynamic step excavation, step-by-step support under the condition of the surrounding rock and supporting structure displacement and stress of tunnel and tunnel are obtained, in the absence of support, first support and a two support 3 different stages of rock plastic zone distribution and failure mechanism [7].

X.G. Jin combined with the underground engineering practice in high geo stress zone, put forward recovery testing and lag stress monitoring method of underground engineering surrounding rocks surface two stress field, the correctness of the application of the theory of elastic mechanics and single hole stress relief method to test the test results [8].

W. Liang is in the construction of the Xiamen Xiangan subsea tunnel at both ends of the terrestrial segment by CRD method of long distance water through the soft layer as the research object, through analysis and construction combined with field monitoring data and calculation software, the discussion of CRD tunnel and its amount in each heading proportion during excavation and construction sequence of heading the settlement of [9].

X.Y. Chen summarizes and analyzes the mechanical characteristics of tunnel surrounding rock, excavation and support construction prone to problems in the work and experience combined with 
the proposed tunnel, broken surrounding rock tunnel excavation and supporting scheme of improvements, a reference and help to the construction of tunnel under similar conditions [10].

Combined with the engineering case, cross diaphragm method and the method of double side to ensure the stability of surrounding rock and tunnel deformation control has the advantage of control standards based on surface settlement project, from the perspective of construction process and construction mechanics, a comparative analysis of two kinds of construction methods, get the tunnel construction scheme optimization.

\section{ENGINEERING SURVEY}

L.G. Mu tunnel is a key project of control national highway network in Shandong Province, as a separate tunnel, through the ruins of the Qi Great Wall, two-way six lane design, $750 \mathrm{M}$. The tunnel was buried deep and buried 15 meters deep at the site of the Great Wall site. The tunnel site is a low mountain geomorphic area with erosion, and the vegetation on the surface is more developed. The lithology of the surrounding rock is granite, the weathering is serious, the fracture is broken, and the joints are developed. In turn, the strata are revealed to be cultivated soil, strong weathered granite and medium weathered granite. The surrounding rock is broken and coarse granular structure, and the grade of surrounding rock is $\mathrm{V}$ class rock.

\section{CONTROL OF SURFACE SUBSIDENCE}

L.G. Mu tunnel belongs to shallow large-span highway tunnel, and the surface has ruins of the Qi Great Wall, engineering conditions and surface conditions are complex, determines the complexity of construction, in order to ensure the safety of cultural relics of the surface, and the stability of tunnel structure and surrounding rock, before the construction, should protect cultural relics sites on the basis of establishing control of land subsidence as a standard, construction monitoring indicators, guide the construction, and ensure the safety of the site of cultural relics.

Starting from the formation and ensure the stability of the structure, the ground settlement control standard necessity and geological conditions, the local construction scale, structure depth, structure size and construction method, at present develop on the ground settlement standard used in 
classification, model test method, numerical calculation and theoretical analysis. According to the engineering characteristics, based on a large number of practical projects, combined with the engineering requirements of the engineering analogy, to determine the appropriate ground settlement standard, then according to the analysis results of the model test and numerical methods are provided to evaluate the construction method and rationality, is an effective method to identify and validate the ground control standard. According to the actual situation of the project, the control standard of surface subsidence is determined at $10 \mathrm{~mm}$.

\section{THREE DIMENSIONAL NUMERICAL SIMULATION}

Tunnel excavation and formation is closely related to the strata structure model to analyze the deformation in materials, elasto-plastic analysis, large deformation analysis and the advantages of simulating the construction process of underground engineering, calculated by large commercial software FLAC3D, the three-dimensional numerical model is established, combined with the geological conditions of the tunnel, support design and the regularity of deformation analysis of surface subsidence and strata control.

\subsection{Calculation hypothesis}

In the process of numerical simulation, the following assumptions are made:

(1)Assuming that the rock mass is homogeneous continuum, its physical and mechanical behavior is calculated according to the Mohr-Coulomb yield criterion. The physical and mechanical behavior of the presupport is calculated by elastic material.

(2)The stress of the geological structure is neglected and the initial stress field is represented by the self gravity stress.

(3)The effect of groundwater is not considered.

\subsection{CALCULATION MODEL AND BOUNDARY CONDITION}

The direction of the excavation along the axis of the tunnel is the positive direction of the $\mathrm{Y}$ axis, 
the vertical direction is vertical to the $\mathrm{Z}$ axis, and the tunnel heading is facing the right direction of the right direction to the right direction of the $\mathrm{X}$ axis. In order to reduce the boundary effect, considering the tunnel span of 3 times the tunnel span, the size of the calculation model is $200 * 100 * 100$ meters, and the depth of the buried tunnel is 15 meters. The three dimensional numerical calculation model of the two tunnel construction methods are shown in Fig. 1 and Fig. 2.
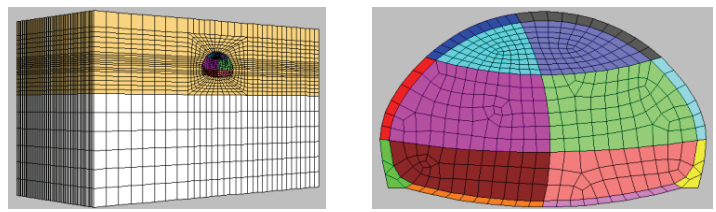

Fig. 1. Three-dimensional model diagram of center cross-diagram method
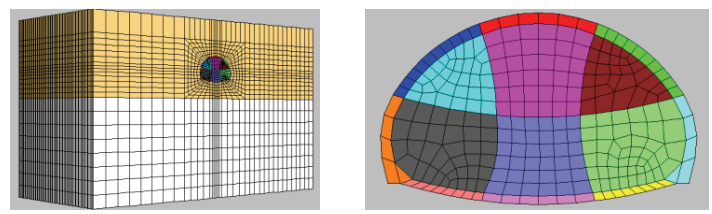

Fig. 2. Three-dimensional model diagram of double sidewall drift method

The model for the side and bottom side limit displacement boundary, horizontal movement, vertical movement of the bottom limit, on the boundary surface of the free surface, the boundary condition model for displacement constraint model is around $\mathrm{X}$ axis, and $\mathrm{Y}$ axis by displacement constraint, displacement constraint is lower in the $\mathrm{Z}$ axis direction, surface for the free boundary, boundary condition calculation model is shown in Fig. 3.

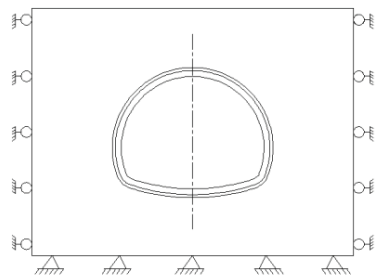

Fig. 3. Boundary conditions for calculating model 


\subsection{CALCULATION PARAMETERS}

The primary support is C25 shotcrete, the inverted arch is filled with C20 concrete, and two is $\mathrm{C} 30$ reinforced concrete, and the thickness is $55 \mathrm{~cm}$. The calculation of structural parameters in the calculation is shown in Table 1 .

Table 1. Main physical and mechanical indexes of the structure

\begin{tabular}{|c|c|c|c|}
\hline Structural type & $\mathrm{E}(\mathrm{GPa})$ & $\mu$ & $\gamma\left(\mathrm{kN} / \mathrm{m}^{3}\right)$ \\
\hline Shotcrete & 24.0 & 0.25 & 2200 \\
\hline Inverted arch & 22.0 & 0.25 & 2200 \\
\hline
\end{tabular}

\subsection{PARAMETERS OF SURROUNDING ROCK}

In the modeling, the stratum is regarded as an ideal elastic-plastic material of Mohr Coulomb. Combined with geological exploration data and reference to the code for design of railway tunnel TB10003-2005, the rock surrounding rock parameters are determined. The basic information parameters of the surrounding rock are shown in Table 2.

Table 2. Parameters of surrounding rock

\begin{tabular}{|c|c|c|c|c|c|}
\hline Material type & $\gamma\left(\mathrm{kN} / \mathrm{m}^{3}\right)$ & $\mathrm{c}(\mathrm{MPa})$ & $\varphi\left(^{\circ}\right)$ & $\mu$ & $\mathrm{E}(\mathrm{GPa})$ \\
\hline V-class surrounding rock & 19.0 & 0.15 & 26 & 0.36 & 1.5 \\
\hline
\end{tabular}

\section{ANALYSIS OF CALCULATION RESULTS}

\subsection{ANALYSIS OF DISPLACEMENT OF SURROUNDING ROCK}

Determine the tunnel deformation and displacement of surrounding rock is an important indicator of the stability, settlement of vault settlement and the surface which is the key index to reflect the impact of tunnel construction on the surface environment, through the analysis of the cross and double side tunnel surrounding rock deformation, compare two different tunnel construction methods influence on surface deformation of surrounding rock relics, see Fig. 4 and Fig. 5. 


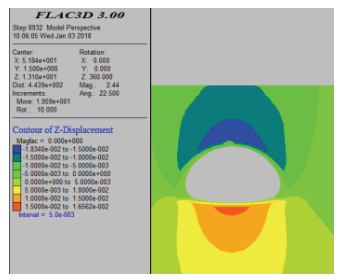

Fig. 4. Cloud map of the vertical displacement of center cross-diagram method

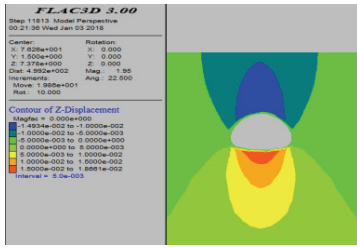

Fig. 5. Cloud map of the vertical displacement of double sidewall drift method

Table 3. Maximum deformation table for the vault settlement and the surface settlement of two tunnel construction methods (unit: $\mathrm{mm}$ )

\begin{tabular}{|c|c|c|}
\hline Type of construction method & Vault settlement & Ground subsidence \\
\hline Center cross-diagram method & 18.3 & $11.2 \mathrm{~mm}$ \\
\hline Double sidewall drift method & 14.9 & $9.6 \mathrm{~mm}$ \\
\hline
\end{tabular}

Through the map and the table, two different construction methods, the maximum deformation of the tunnel in the vault settlement, the vault settlement of center cross-diagram method is $18.3 \mathrm{~mm}$, the vault settlement of double sidewall drift method is $18.3 \mathrm{~mm}$, the maximum surface settlement of center cross-diagram method is $11.2 \mathrm{~mm}$, the maximum surface settlement of double sidewall drift method is $9.6 \mathrm{~mm}$; based on surface sites the protection criterion, meet the requirements of the settlement of double side surface, beyond the standard value of surface subsidence in the next crossing, in controlling the deformation of surrounding rock, double sidewall drift method outperforms the center cross-diagram method.

\subsection{ANALYSIS OF THE INTERNAL FORCE OF PRIMARY SUPPORT}

The primary support is combined with the surrounding rock, and the initial internal force is the key index to measure the stability of the tunnel. The initial internal forces of the two different construction methods are shown in Fig. 6 and Fig. 7. 


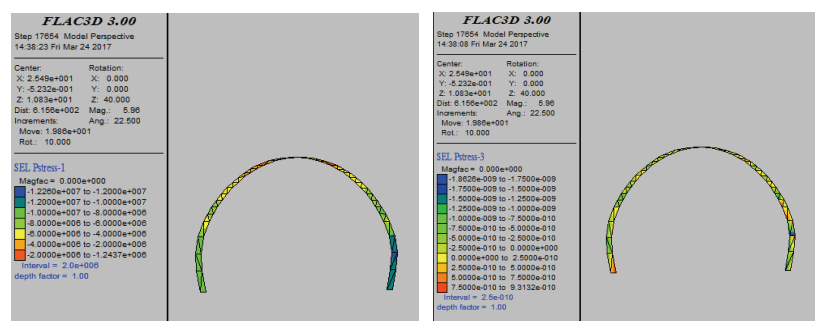

Fig. 6. Main stress of primary support of center cross-diagram method
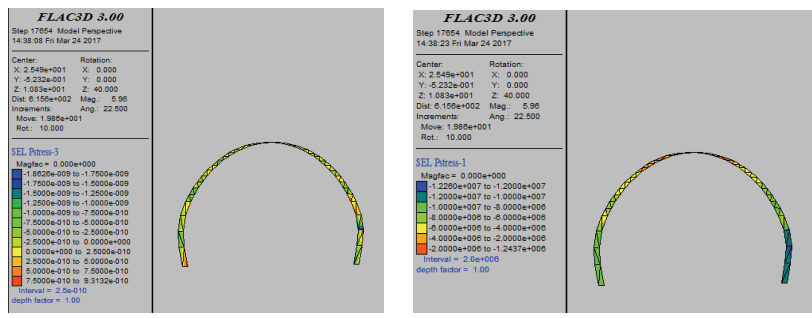

Fig. 7. Main stress of primary support of double sidewall drift method

Initial stress mainly is the compressive stress, the maximum principal stress in the next cross $12.3 \mathrm{Mpa}$, the maximum principal stress method of double side is $18.2 \mathrm{Mpa}$, in the strength of the material within the allowable range, indicating a good stability of surrounding rock, the surrounding rock deformation control, a better method of double side effect, initial stress is greater than the next cross method.

\subsection{THE SCOPE OF THE PLASTIC ZONE}

The effect of bolt support on the plastic zone is represented by plastic range. The distribution of plastic zone after excavation by two different construction methods is shown in Fig. 8 and Fig. 9 .

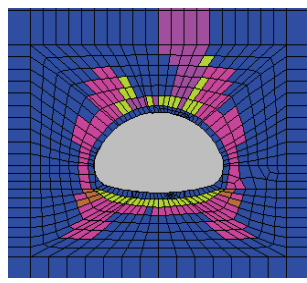


Fig. 8. Distribution of plastic zone of center cross-diagram method

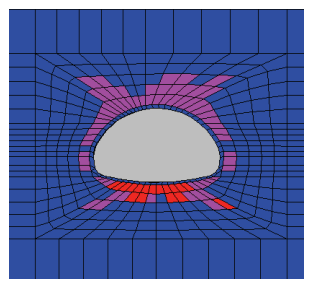

Fig. 9. Distribution of plastic zone of double sidewall drift method

Used center cross-diagram method after the tunnel excavation, the distribution of plastic zone on both sides of the main arch on both sides of the shoulder, and right at the crown, because right after the sequence of excavation disturbed many times, the plastic zone of the surrounding rock through to the surface, both side walls on the plastic zone through forming a tunnel connected to the ring, plastic zone and the formation of a large range of plastic zone of surrounding rock, tunnel excavation serious influence the ground surface. Used double sidewall drift method after the tunnel excavation, the distribution of plastic zone in the main vault and invert bottom, side walls of the plastic zone, side wall and arch and the plastic zone is not through, right after the order due to excavation, the vault and the arch bottom received two construction disturbance, the plastic zone is not communicated to the surface and ensure the integrity of rock surface.

\section{CONCLUSION}

Based on the safety of surface relics, making the settlement standard, through three-dimensional numerical calculation software of center cross-diagram method and double sidewall drift method was simulated. The calculation results show that the deformation of surrounding rock control, the double sidewall drift method outperforms the center cross-diagram method. Using the center cross-diagram method meet the requirements of surface subsidence control and ensure the stability of the tunnel, which is preferred by tunnel construction. 


\section{ACKNOWLEDGMENTS}

This work was supported by the Natural Science Foundation of China (grant number 51704125); the China Postdoctoral Science Foundation (grant number 2017T100491, 2016M602144); and Natural Science Foundation of Shandong Province, China (grant number ZR2017QEE013).

\section{REFERENCES}

1. Y. Q. Liu, S. H. Zhong, LU Rusui, et al, "Experimental study on mechanical characteristics of twin tunnels with small spacing”, Chinese Journal of Rock Mechanics and Engineering 19(5): 590-594, 2000.

2. X. G. Jin, L. S. Wang, H. Wei, "Surrounding rock deformation monitor and application in highway tunnel", The Chinese Journal of Geological Hazard and Control 11(1): 19-23, 2000.

3. T. L. Cui, "Structural internal force monitoring and stability analysis on primary lining bored tunnel with a shallow depth", Modern Tunnelling Technology 38(11): 29-34, 2001.

4. A. Q. Wu, P. Xu, C. M. Xu, et al, "Researches on stability for surrounding rock masses of underground power house in the Three Gorges Project", Chinese Journal of Rock Mechanics and Engineering 20(5): 690-695, 2001.

5. Y. Z. Lu, W. W. Yang, "Research on construction scheme of Lianhuashan double-arch rock tunnel", China Journal of Highway and Transport 14(4): 75-77, 2001.

6. M. J. WU, L. H. Huang, "Research on dynamic construction mechanics of four-lane highway tunnel”, Chinese Journal of Rock Mechanics and Engineering 25(2): 3057-3062, 2006.

7. W. Q. Ding, X. X. Wang, Z. G. Li, et al, "Optimal analysis of construction schemes for shallow large-span Longshan twin tunnel”, Chinese Journal of Rock Mechanics and Engineering 24(22): 4042-4047, 2005.

8. Y. X. Zhang, M. F. Cai, L. Qiao, et al, "Study on mechanical response to excavation and support of expressway tunnel", Chinese Journal of Rock Mechanics and Engineering 25(6): 1284-1289, 2006.

9. X. G. Jin, L. S. Wang, X. H. Li, "Site testing and monitoring of induced stress field in surrounding rocks of underground engineering", Chinese Journal of Rock Mechanics and Engineering 21(5): 651-653, 2002.

10. W. Liang, M. L. Huang, "Subsidence and deformation control of large-span tunnel in water-bearing unfavorable geological conditions with CRD method", Chinese Journal of Rock Mechanics and Engineering 26(2): 3788-3742, 2007

11. X. Y. Chen, Y. C. Tang, J. J. Wen, "The improvement scheme for excavation and support of tunnel in crashed wall-rocks", Journal of Chang'an University(Earth Science) 25(9): 60-62, 2003. 


\section{LIST OF FIGURES AND TABLES:}

Fig. 1. Three-dimensional model diagram of center cross-diagram method

Fig. 2. Three-dimensional model diagram of double sidewall drift method

Fig. 3. Boundary conditions for calculating model

Fig. 4. Cloud map of the vertical displacement of center cross-diagram method

Fig. 5. Cloud map of the vertical displacement of double sidewall drift method

Fig. 6. Main stress of primary support of center cross-diagram method

Fig. 7. Main stress of primary support of double sidewall drift method

Fig. 8. Distribution of plastic zone of center cross-diagram method

Fig. 9. Distribution of plastic zone of double sidewall drift method

Table 1. Main physical and mechanical indexes of the structure

Table 2. Parameters of surrounding rock

Table 3. Maximum deformation table for the vault settlement and the surface settlement of two tunnel construction methods (unit: $\mathrm{mm}$ ) 


\section{OPTIMIZATION ANALYSIS OF CONSTRUCTION SCHEME FOR LARGE-SPAN HIGHWAY TUNNEL UNDER COMPLEX CONDITIONS}

Keywords: similar materials, large-span, center cross-diagram method, double sidewall drift method

\section{SUMMARY}

The construction process of the tunnel ground deformation regularity of surrounding rock, stability, deformation control of tunnel surface based on the requirements, combined with the characteristics of shallow tunnel with large-span. Used three-dimensional numerical simulation software, established a dynamic tunnel analysis program to simulate the construction process of center cross-diagram method and double sidewall drift method. Based on the stratum deformation, supporting force and analysis of plastic zone distribution, comparative analysis of engineering adaptability of different construction methods from the construction process and construction mechanics, get optimization tunnel construction scheme.

L.G. Mu tunnel belongs to shallow large-span highway tunnel, and the surface has ruins of the Qi Great Wall, engineering conditions and surface conditions are complex, determines the complexity of construction, in order to ensure the safety of cultural relics of the surface, and the stability of tunnel structure and surrounding rock, before the construction, should protect cultural relics sites on the basis of establishing control of land subsidence as a standard, construction monitoring indicators, guide the construction, and ensure the safety of the site of cultural relics.

Starting from the formation and ensure the stability of the structure, the ground settlement control standard necessity and geological conditions, the local construction scale, structure depth, structure size and construction method, at present develop on the ground settlement standard used in classification, model test method, numerical calculation and theoretical analysis. According to the engineering characteristics, based on a large number of practical projects, combined with the engineering requirements of the engineering analogy, to determine the appropriate ground settlement standard, then according to the analysis results of the model test and numerical methods are provided to evaluate the construction method and rationality, is an effective method to identify and validate the ground control standard. According to the actual situation of the project, the control standard of surface subsidence is determined at $10 \mathrm{~mm}$.

Tunnel excavation and formation is closely related to the strata structure model to analyze the deformation in materials, elasto-plastic analysis, large deformation analysis and the advantages of simulating the construction process of underground engineering, calculated by large commercial software FLAC3D, the three-dimensional numerical model is established, combined with the geological conditions of the tunnel, support design and the regularity of deformation analysis of surface subsidence and strata control. 
The direction of the excavation along the axis of the tunnel is the positive direction of the $\mathrm{Y}$ axis, the vertical direction is vertical to the $\mathrm{Z}$ axis, and the tunnel heading is facing the right direction of the right direction to the right direction of the $\mathrm{X}$ axis. In order to reduce the boundary effect, considering the tunnel span of 3 times the tunnel span, the size of the calculation model is $200 * 100 * 100$ meters, and the depth of the buried tunnel is 15 meters. The three dimensional numerical calculation model of the two tunnel construction methods are shown in Fig. 1 and Fig. 2.

The model for the side and bottom side limit displacement boundary, horizontal movement, vertical movement of the bottom limit, on the boundary surface of the free surface, the boundary condition model for displacement constraint model is around $\mathrm{X}$ axis, and $\mathrm{Y}$ axis by displacement constraint, displacement constraint is lower in the $\mathrm{Z}$ axis direction, surface for the free boundary, boundary condition calculation model is shown in Fig. 3.

Determine the tunnel deformation and displacement of surrounding rock is an important indicator of the stability, settlement of vault settlement and the surface which is the key index to reflect the impact of tunnel construction on the surface environment, through the analysis of the cross and double side tunnel surrounding rock deformation, compare two different tunnel construction methods influence on surface deformation of surrounding rock relics, see Fig. 4 and Fig. 5 .

Through the map and the table, two different construction methods, the maximum deformation of the tunnel in the vault settlement, the vault settlement of center cross-diagram method is $18.3 \mathrm{~mm}$, the vault settlement of double sidewall drift method is $18.3 \mathrm{~mm}$, the maximum surface settlement of center cross-diagram method is $11.2 \mathrm{~mm}$, the maximum surface settlement of double sidewall drift method is $9.6 \mathrm{~mm}$; based on surface sites the protection criterion, meet the requirements of the settlement of double side surface, beyond the standard value of surface subsidence in the next crossing, in controlling the deformation of surrounding rock, double sidewall drift method outperforms the center cross-diagram method. 